between PlasmaLyte and the fluid preparations currently used in this trust indicated that PlasmaLyte and PlasmaLyte with $5 \%$ glucose is more cost-effective. PlasmaLyte is already used by the regional paediatric transport service.

Conclusion PlasmaLyte (and PlasmaLyte with 5\% glucose) constitutes a safe, cost-effective intravenous fluid for most paediatric patients, which conforms to best practice. Furthermore, streamlining of intravenous fluid choice both within the trust and the wider paediatric network reduces confusion, promoting safety and continuity of care. Overall, PlasmaLyte (and PlasmaLyte with $5 \%$ glucose) constitutes a suitable fluid of choice for use in all paediatric patients in the trust, unless specifically contraindicated.

\section{G136(P) MARKETING PAEDIATRICS - AN INTER-GENERATIONAL COLLABORATION}

K Galllagher, W Kelsall. Paediatrics, Addenbrooke's Hospital, Cambridge, UK

\subsection{6/archdischild-2018-rcpch.132}

Aims Applications for ST1 training in paediatrics in the United Kingdom fell by $27.5 \%$ from 2015 to 2017 as follows: 800 applicants in 2015 to 743 in 2016 and 580 in 2017. There were a similar number of posts advertised each year. In 2017 the overall fill-rate of ST1 paediatric training posts was $83 \%$ necessitating the RCPCH to re-advertise ST1 posts and conduct second-round interviews for the first time. Between 2013 and 2016 there has been a $27.2 \%$ fall in the number of F1 doctors planning to apply to paediatric training.

We have developed a number of strategies to improve recruitment. We noted that there were limited visual resources on line to inform and attract potential trainees to paediatrics training, especially in our region.

Methods In conjunction with a team of four sixth-form students who were pursuing media/film studies and were keen to undertake a service project, we embarked on the creation of an online video. Multiple project-planning meetings were required so that students could understand the target audience and purpose of the video, i.e. capturing the essence of being a paediatric trainee in our programme. Patients and their families gave their consent to participate in this project.

Results An eight-minute, trainee-focussed video of high quality was created to attract junior doctors to paediatric training in this deanery. In producing this video, current trainee engagement was incredibly enthusiastic, with a keen sense of a paediatric community in the deanery. It highlights our achievements as a School of Paediatrics, including the PAFTAs and outstanding support for academic training. Patient participation demonstrated that junior doctors were valued and appreciated. The sixth form students gained the experience they required in producing short films.

Conclusion This example of our work to recruit junior doctors to paediatric training in our region was a fantastic way to engage young people in an inter-generational collaboration to benefit the wider community. We are very proud of this video, of our region and hope this will be reflected with better recruitment and retention of doctors in the future. We encourage other regions to consider similar projects to enhance recruitment.

\section{G137(P) ARE PHYSICIAN ASSOCIATES THE ANSWER TO PAEDIATRIC ROTA GAPS?}

LR Wade, S Hulikere. General Paediatrics, Warrington and Halton Hospitals NHS Foundation Trust, Warrington, UK

\subsection{6/archdischild-2018-rcpch.133}

Aims Physician Associates roles have been proposed as a solution to junior medical workforce gaps. We carried out a survey to assess how prepared student Physician Associates (PAs) felt near the end of their two-year course and their current career plans.

Methods The first cohort of student PAs funded by Health Education North West finish training in January 2018 and were invited to a recruitment day at Warrington hospital. A questionnaire survey was handed to all 36 attendees, 20 responded. We asked about their career aspirations and to rate how well they felt their course had prepared them to perform aspects of their role as defined by the Faculty of Physician Associates. We used a 1-5 rating system with $1=$ not prepared at all and $5=$ very well prepared.

Results $75 \%$ were females and $90 \%$ were in the age group $<30$ years. All the students held a life science degree but only $70 \%$ had some previous work experience. Student PAs felt well prepared in the areas of history taking and examination with $90 \%$ and $85 \%$ scoring 4 or more respectively. Most also felt confident in making a diagnosis, 75\% scored 4 or more. The student PAs felt less prepared to interpret test results and formulate management plans with $55 \%$ and $50 \%$ scoring 4 or more respectively. With regards to career aspirations $65 \%$ wanted to work within $\mathrm{A}$ and $\mathrm{E}$ or acute medicine, the remaining 35\% were undecided.

Conclusion It appears that PAs need more support in interpreting test results and management plans. The recruiting teams need to focus on this during their initial placements and provide appropriate mentoring and supervision support. Within this cohort of student PAs, paediatrics did not seem to be a popular choice. However, 35\% of them were undecided on future career plans. As a paediatric community we need to make the specialty more attractive when PAs rotate in the department if we want them to address our junior medical workforce gaps.

\section{G138(P) ACUTE BRONCHIOLITIS: VARIATIONS IN INTRAVENOUS FLUID ADMINISTRATION}

S Evans, R Mills, T Ninan. Paediatrics, Heart of England Foundation Trust, Birmingham, UK

\subsection{6/archdischild-2018-rcpch.134}

Introduction Bronchiolitis is the most common cause of hospitalisation during infancy. Management is primarily supportive. Increased respiratory effort and decreased fluid intake increase the risk of dehydration and in severe cases, intravenous (IV) fluid therapy is required. Over the past decade there has been a shift from hypotonic to isotonic fluid prescription as hyponatraemia is a recognised complication of IV therapy with potentially fatal consequences. This risk is increased in infants with respiratory syncytial virus (RSV) bronchiolitis due to increased anti-diuretic hormone secretion. This is reflected in 
the NICE bronchiolitis guidelines (NG9) which now recommends isotonic fluids.

Aim To investigate patterns of IV fluid administration and analyse plasma sodium measurements in children with bronchiolitis admitted to a busy paediatric unit.

Methods Audit of all infants with bronchiolitis, on IV fluids between November 2016 and January 2017. The audit protocol was derived from NICE guidance (NG9).

Results Thirty- two out of 237 patients admitted with bronchiolitis received IV fluids (13.5\%). Data was available for twenty- nine infants. The median age was 7 weeks and the majority were male $(n=20)$. The most common pathogen isolated was RSV in $85.7 \%$ of cases.

Seventeen (58.6\%) infants received isotonic fluids however, 16 $(55.2 \%)$ received hypotonic or a mixture of hypotonic and isotonic solutions. Two infants were hyponatraemic on admission (sodium $121 \mathrm{mmol} / \mathrm{L}$ and $129 \mathrm{mmol} / \mathrm{L}$ respectively), however none developed iatrogenic hyponatraemia. There was a single case of hypernatraemia in the isotonic fluids group (sodium $147 \mathrm{mmol} / \mathrm{L}$ ). There was no significant difference in change in sodium between those receiving purely hypotonic or isotonic solutions. Moreover, there was no association observed between rate of IV infusion (boluses not included) and change in sodium however, there was a significant association with duration of intravenous fluids $(p=0.012)$. Two infants had large variations in plasma sodium of 10 and $12 \mathrm{mmol} / \mathrm{L}$ respectively.

Conclusions Significant changes in plasma sodium can occur whilst children are receiving IV fluids. This highlights the importance of regular electrolyte monitoring and regular assessment of the need for on-going fluid administration.

\section{G139(P) AWARDS FOR EXCELLENCE IN PAEDIATRICS: A TRAINEES' PERSPECTIVE IN IMPROVING MORALE}

L Rowley, I Misra, J Srinivas. Paediatrics, Milton Keynes University Hospital, Milton Keynes, UK

10.1136/archdischild-2018-rcpch. 135

Background and aims The paediatric team at Milton Keynes University Hospital has a monthly Award for Excellence, where all staff could nominate any other member of staff for excellence at work. We hoped that this would improve team morale by giving opportunity to celebrate the nominated staff and to make staff feel more appreciated.

We analysed the awards over last 12 months to review junior doctors' role in nominating and receiving nominations.

Method Review of nominations for the last 12 months. Designation of staff who filled the nominations and those that were nominated was collected along the reasons for nomination.

Results 54 members of staff were nominated for the Excellence award in the last 12 months. Most of the nominations were by consultants (42\%) and nurses (33\%). Wide ranges of professionals were recommended for these awards but the most common were nurses (44\%) and junior doctors (26\%).

The reasons for nominations were varied and included good communication, hard work, great leadership, compassion and feedback from patients. Informal feedback from few of the award-winning trainees showed that these awards were appreciated and encouraged motivation.
Conclusions Awards for excellence in paediatric is animportantway to appreciate staff that have made a significant positive impact on patient care and teamwork. While the junior doctors were the second most nominated group to receive awards, it is important to notice that they did not nominate any individuals in the last 12 months. One of the reasons might be that they were not aware of these awards and efforts will be made to include this in their future induction sessions. We feel that empowering trainees to nominate staff for these awards will help feel part of the team and receiving these awards will increase their morale. Learning from excellence (Greatix), an online positive feedback tool has recently been launched in our Trust and paediatric nominations will be monitored in the future.

\section{G140(P) GASTROSCHISIS: A 9 YEAR SINGLE CENTRE EXPERIENCE}

L Yee, C Douch, A Zaghal, S Chuang, S Habermann. Neonatal, Chelsea and Westminster Hospital, London, UK

\subsection{6/archdischild-2018-rcpch.136}

Aims To describe the outcomes of all babies with gastroschisis managed over a 9 year period at a single surgical unit.

Methods Retrospective study of all infants with gastroschisis, repaired between Jan 2007 to Jan 2016. They were analysed according to Simple vs Complex Gastroschisis and the Simple group subdivided into Primary vs Staged Closure.

Results We identified 56 babies. There were 45 simple and 10 complex cases. One baby was excluded with a closed gastroschisis. 26 babies with Simple Gastroschisis had primary and 19 had staged closure.

No deaths were noted. No significant differences in operative complications and unplanned re-operations were demonstrated. The median length of stay, time to full feeds and parenteral nutrition duration was not significantly different between simple and complex gastroschisis groups.

There was a significant difference in days to first feed and parenteral nutrition duration in Simple Gastroschisis managed with Primary closure and Staged closure (table 1).

\section{Abstract G140(P) Table 1}

\begin{tabular}{lllll}
\hline & Simple, staged & Simple, primary & Mean diff & P value \\
\hline Days to first feed & 9.5 & 18 & $8(3-17)$ & $<0.001$ \\
Days to full feed & 21 & 31 & $8(0-24)$ & 0.04 \\
Day of parenteral nutrition & 21 & 33 & $11(2-21)$ & 0.01 \\
\hline
\end{tabular}

\section{Conclusions}

1. Simple vs Complex Gastroschisis:

a. There was a higher but non significant risk of operative

complications in the complex group.

b. No statistically significant difference between the simple and complex groups. A sizable proportion of complex patients were excluded as they did not achieve outcome or were transferred to other units.

2. Primary vs Staged closure in Simple Gastroschisis:

a. No statistically significant difference in operative complications between primary and staged groups. 